\title{
A COMPARISON STUDY TO DETERMINE THE MEAN OF PARTICLE SIZE DISTRIBUTION FOR TRUTHFUL CHARACTERIZATION OF ENVIRONMENTAL DATA (PART 1)
}

\author{
M.M. Ahmed and S.S. Ahmed
}

Mining and Metallurgical Engineering Department, Faculty of Engineering, Assiut University, Assiut 71516, Egypt

Email: mamoah2000@yahoo.com.au

(Recieved December 3, 2007 Accepted January 8, 2008)

One of the most important steps in environmental studies is to get an accurate distribution of the pollutants in terms of its quantity and qualities. Some environmental studies are acquiring a good classification of the particle size including the average mean of the particle. Many researchers use the median size $\left(x_{50}\right)$ or until the size passing $80 \%$ cumulative undersize $\left(x_{80}\right)$ as a measure for evaluation of the particle size distribution resulted from different mineral processing operations such as crushing, grinding, classification, sedimentation, and/or solid-liquid separation or even during the study of the pollutant settlement. These measures are not so accurate to differentiate between different particle size distributions (PSDs) because many PSDs data sets may have the same values of $x_{50}$ or $x_{80}$ if these data sets are represented between the particle size, $x$ and the cumulative undersize distribution, $F$ (x). This paper is a trial to introduce a new methodology to determine the mean of a particle size distribution (MPSD) accurately using GatesGaudin-Schuhmann and Rosin-Rammler models. The value of this measure takes into consideration all particle sizes and their corresponding distributions. The results showed that the different PSD, which have the same values of median $\left(x_{50}\right)$ have different values of this measure, especially with Rosin-Rammler model. In this paper, the expressions of different types of means of a particle size distribution (arithmetic, quadratic, cubic, geometric, and harmonic) were derived mathematically using the two mentioned models. It is recommended to select RR model to be applied in estimation of the different means of a particle size distribution because it fits the available data better than the GGS model, as well as, it determines the correct values and exerts the actual differences between the different means of different particle size distribution data sets. This work will be continuing by demonstrating a case study using real environmental data in Part (2).

KEY WORDS: Frequency or density function, distribution function, particle size, mean, Gates-Gaudin-Schuhmann model, Rosin-Rammler model 


\section{NOMENCLATURE}

$c \quad$ the particle size corresponding to $63.2 \%$ cumulative distribution undersize

$f(x) \quad$ particle size distribution frequency function either by number,

length, surface, or mass, whichever may be of interest

$f_{L}(x) \quad$ particle size distribution by length

$f_{M}(x) \quad$ particle size distribution by mass

$f_{N}(x) \quad$ particle size distribution by number

$f_{S}(x) \quad$ particle size distribution by surface

GGS Gates-Gaudin-Schuhmann

$k \quad$ the maximum size of particles which corresponding to $100 \%$ cumulative distribution undersize

$k_{1}, k_{2}, k_{3}$ shape factors

$m$ a characteristic constant of the material under analysis and gives a measure of steepness of cumulative curve

$m(x) \quad$ a certain function of particle size $\mathrm{x}$

$\mathrm{m}(\mathrm{x}) \quad$ the area under the distribution curve with respect to $\mathrm{F}(\mathrm{x})$ axis

MPSD mean of particle size distribution

$n \quad$ a characteristic constant of the material under analysis and gives

a measure of steepness of cumulative distribution curve

PSD particle size distribution

$\mathrm{R}^{2} \quad$ coefficient of correlation

RR Rosin-Rammler

$x \quad$ particle size

$\mathrm{x}_{50}$ the median or the size which corresponds to $50 \%$ cumulative undersize

$\mathrm{x}_{80} \quad$ the size which corresponds to $80 \%$ cumulative undersize

(x) mean diameter

$(\mathrm{x})_{\mathrm{a}} \quad$ arithmetic (length) mean

(x) cubic (volume) mean

(x) geometric mean

$(\mathrm{x})_{\mathrm{h}} \quad$ harmonic (surface volume) mean

$(\mathrm{x})_{\mathrm{q}} \quad$ quadratic (surface) mean

$y=F(x)$ cumulative undersize distribution function

\section{INTRODUCTION}

Primary properties of particles such as the particle size distribution, shape, density, and surface properties govern the secondary properties such as the settling velocities of particles, the permeability of a bed, or the specific resistance of a filter cake. Knowledge of these properties is a vital in the design and operation of mineral processing equipment [1]. 
Particle size is probably the most important single physical characteristic of solids. It influences the combustion efficiency of pulverized coal, the settling time of cements, the flow characteristics of granular materials, the compacting and sintering behavior of metallurgical powders, pharmaceutical products, and the masking power of paint pigment [2]. These examples illustrate the intimate involvement of particle size in energy generation, industrial processes, resource utilization, and many other phenomena [3].

Crushing and grinding operations are employed to fracture mineral aggregates, and thus to increase liberation. The choice of fineness of grinding is an important decision as the ore must be sufficiently finely ground to liberate the valuable minerals. The accurate determination of grain liberation during reduction has a significant impact on the advancing of physical or chemical mineral processing operations. Deriving a measure that can be used to estimate quantitatively the fineness of grinding becomes of great practical utility [4].

The maximum utilization of particle size distribution data can be obtained if the data was represented by a mathematical expression. The mathematical function allows ready graphical representation and offers maximum opportunities for interpretation, extrapolation, and comparison of different PSDs [5]. Furthermore, more useful information can be revealed if the parameters of the function can be related to the properties of the particulate system or process that produces it. This would allow of product control, tighter product specifications and quality assurance [1].

Several parameter mathematical models and expressions have been developed to obtain the distribution and density functions from experimental PSD curves. These functions range from the well-established normal and log-normal distributions to the RR and GGS models [1,3,5]. The RR distribution function has long been used to describe the PSD of powders of various types and sizes. This function is particularly suited to represent powders made by grinding, milling, and crushing operations [3]. Numerous three and four parameter models have also been proposed for greater accuracy in describing particle size distributions. But they have limit applications due to their greater mathematical complexity [1].

\section{AIM OF THE WORK}

Many researchers [5-9] have used the median (x50) or x80 to compare and evaluate different particle size distributions. But, these measures may be not so accurate and enough to differentiate between different distributions because different particle size distributions may have the same values of $x 50$ or $x 80$. The aim of this research is to compare the mean of a particle size distribution (MPSD) estimated from GatesGaudin-Schuhmann and Rosin-Rammler models for different particle size distribution data sets. The value of this index is a valuable and more reliable to be used to differentiate between different PSDs which have the same values of x50. Also, it was derived expressions which can be used to determine mathematically the values of different types of means of a distribution (arithmetic, quadratic, cubic, geometric, and harmonic) using the two mentioned models. This paper may be the first one developed to derive the mean of a particle size distribution from Gates-Gaudin-Schuhmann and Rosin-Rammler models. 


\section{TYPES OF PARTICLE SIZE ANALYSIS}

An irregular particle can be measured by a number of different sizes which depend on the dimension and/or property studied. There are basically three groups of sizes, namely, equivalent sphere diameter, equivalent circle diameter, and statistical diameter [10]. The first type of sizes is defined as the diameter of a sphere which would have the same property as the particle itself (the same volume, the same projected area, the same settling velocity, etc.). The second type of sizes is defined as the diameter of a circle that would have the same property as the projected outline of the particle. The statistical diameter is obtained when a linear dimension parallel to a fixed direction is measured [1,5].

Many methods have been developed to determine the size distribution of particulate system [11-12]. A number of methods aimed at determining PSDs (i.e., sieving, cycloning, microscopy, etc.) have been described [13]. Using different characterization techniques for the PSD analysis of a material, one may obtain quite radically different information and different measures of size [14-15]. Hence, any analysis technique used will depend on the ultimate goal of the characterization [3].

In methods of solid-liquid separation at which the motion of a particle relative to the fluid is the governing mechanism, it is of course most relevant to use a method which measures the free-falling diameter or, more often, the Stokes' diameter [5,10]. In liquid filtration on the other hand, the surface volume diameter is more relevant to the mechanism of separation because the resistance to flow through packed beds depends on the specific surfaces of the particles that make up the bed [1].

\section{TYPES OF PARTICLE SIZE DISTRIBUTIONS (PSDS)}

Four different types of a particle size distribution may be defined, as follows:

1. Particle size distribution by number, $\mathrm{f}_{\mathrm{N}}(\mathrm{x})$.

2. Particle size distribution by length, $\mathrm{f}_{\mathrm{L}}(\mathrm{x})$.

3. Particle size distribution by surface, $\mathrm{f}_{\mathrm{S}}(\mathrm{x})$.

4. Particle size distribution by mass, $\mathrm{f}_{\mathrm{M}}(\mathrm{x})$.

Although that the above distributions are related together, the conversion from one distribution to another is possible only when the shape factor is constant, i.e. particle shape is independent on particle size. The following relationships show the basis of such conversion [1]:

$$
\begin{aligned}
& f_{L}(x)=k_{1} x f_{N}(x) \\
& f_{S}(x)=k_{2} x^{2} f_{N}(x) \\
& f_{M}(x)=k_{3} x^{3} f_{N}(x)
\end{aligned}
$$

The constants $k_{1}, k_{2}$, and $k_{3}$ contain the shape factor which depends often on particle size distribution. This assures that the accurate conversion from one type of particle size distribution to another is not possible without a full quantitative knowledge of the shape factor's dependence on particle size. These constants can easily be found if the shape of particles does not vary with size. 
From the definition of frequency distribution, the area under the frequency curve against particle size should be equal to one. This can be revealed by the following equation [16-17]:

$$
\int_{0}^{\infty} f(x) d x=1.0
$$

where: $\mathrm{f}(\mathrm{x})$ = particle size distribution frequency function either by number, length, surface, or mass, whichever may be of interest

Different methods give different particle size distributions and the selection of the method is made on the basis of particle size and the type of distribution required. In most applications, particle size distribution by mass is of interest. There are, however, cases such as liquid clarification where the turbidity of the overflow is of importance and particle size distribution by surface or even by number are more relevant [1].

\section{Representation of the Particle Size Distribution Data}

Particle size distribution data are given either in an analytical form (as a function) or as a set of data in a table or a diagram. The distributions are represented as frequencies, $f$ $(x)$ or cumulative frequencies, $F(x)$ which mutually corresponds because the frequency curve can be obtained by differentiation of the cumulative curve as follows $[16,18]$ :

$$
f(x)=\frac{d F(x)}{d x}
$$

or vice versa, the cumulative curve, $F(x)$ can be obtained by integration of the frequency curve, $f(x)$, i.e.:

$$
F(x)=\int f(x) d x
$$

where: $\mathrm{F}(\mathrm{x})$ = cumulative undersize distribution function.

The area under the frequency curve is, by definition, equal to 1.0 as given in equation (4), so that $F(x)$ goes from 0 to 1.0 or $100 \%$. The cumulative percentages are given as either oversize or undersize, which mutually correspond, because the sum of oversize and undersize fractions are equal to one at any given particle size $[1,16]$.

\section{The Measures of a Particle Size Distribution}

There are great number of different average or mean sizes which may be defined for a given particle size distribution. The purpose of such measures is to represent a population of particles by a single figure. There are three important measures for a given particle size distribution. These are the mode, the median, and the mean $[9,16,19]$.

\section{a. The mode}

The mode is defined as the most commonly occurring size or the size corresponding to the peak on the size distribution frequency curve. This measure is not a valid for comparisons of different distributions because some distributions may have more than one peak and are commonly referred to as multi-modal distributions $[1,16]$. 


\section{b. The median}

The median or the $50 \%$ size $\left(\mathrm{x}_{50}\right)$ is the size at which half of the particles are larger and the other half are smaller. The median is most easily determined from the cumulative undersize or oversize curves, i.e. it is the size which corresponds to $50 \%$. This measure may be not also so accurate and valuable measure to differentiate between different particle size distributions (PSDs) data because different particle size distribution data sets may have the same values of median $[1,5,20]$.

\section{c. The mean}

It is the average of particle sizes and is a very valuable measure for the sample. There are many mean diameters that can be defined for a given particle size distribution. Their definitions are, in a general form, as follows $[1,9,16]$ :

$$
m(\bar{x})=\int_{0}^{\infty} m(x) f(x) d x
$$

where:

$m(x)=$ a certain function of particle size $x$

$\mathrm{m}(\mathrm{x}) \quad=$ mean diameter

Depending on the form of this function, there are several types of mean diameters as shown in Table $\mathbf{1}[1,9]$.

Evaluation of the various means required for a given particle size distribution is based on equation (7). By substituting of equation (5) into equation (7), the latter can be rewritten as follows:

$$
m(\bar{x})=\int_{0}^{1.0} m(x) d y
$$

where:

$\mathrm{y}=\mathrm{F}(\mathrm{x})=$ cumulative undersize distribution function

Table 1: Types of mean diameters of a distribution

\begin{tabular}{|c|c|}
\hline Name of mean diameter $(\mathrm{x})$ & Form of m $(\mathbf{x})$ \\
\hline Arithmetic (length) mean $(\mathrm{x})_{\mathrm{a}}$ & $\mathrm{m}(\mathrm{x})=\mathrm{x}$ \\
\hline Quadratic (surface) mean $(\mathrm{x})_{\mathrm{q}}$ & $\mathrm{m}(\mathrm{x})=\mathrm{x}^{2}$ \\
\hline Cubic (volume) mean $(\mathrm{x})_{\mathrm{c}}$ & $\mathrm{m}(\mathrm{x})=\mathrm{x}^{3}$ \\
\hline Geometric mean $(\mathrm{x})_{\mathrm{g}}$ & $\mathrm{m}(\mathrm{x})=\operatorname{Ln}(\mathrm{x})$ \\
\hline Harmonic (surface volume) mean $(\mathrm{x})_{\mathrm{h}}$ & $\mathrm{m}(\mathrm{x})=1 / \mathrm{x}$ \\
\hline
\end{tabular}




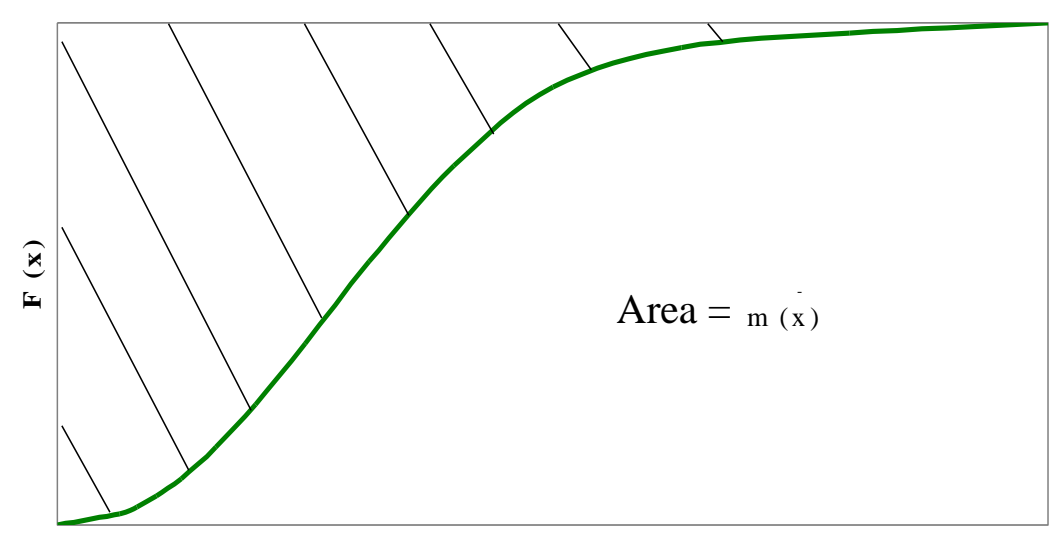

m $(\mathbf{x})$

Fig. 1: Evaluation of a mean ( $\mathrm{x}$ ) of a particle size distribution from the cumulative undersize distribution function $(\mathrm{F}(\mathrm{x}))$

If either frequency function, $f(x)$, or cumulative undersize distribution function, $F(x)$ is available as analytical functions, the desired mean is evaluated by integration of equations (7) or (8), respectively. If, however, no analytical function is fitted and the particle size distribution is in the form of a graph or a table, evaluation of mean diameters can be best done graphically. If the cumulative undersize function, $F$ $(x)$ was plotted against $m(x)$ for the corresponding type of size required, the mean size, $\mathrm{m}(\mathrm{x})$ is then represented by the area under the curve with respect to $F(x)$ axis as illustrated in Figure 1 [1]. The mean size is evaluated from this area using the corresponding equation for $m(x)$ as shown in Table 1.

\section{Determination of the Mean of Particle Size Distribution (MPSD) Using Gates-Gaudin-Schuhmann Distribution Model:}

Referring to the availability of many progressive computer softwares, it is more convenient to fit the experimental particle size distribution data with an analytical function and to use this function mathematically in further treatment. It can be decided that it is easier to evaluate the mean size from analytical functions more than from experimental data. The Gates-Gaudin-Schuhmann distribution function is a widely used function which is usually applied to evaluate the particle size distribution data resulted from comminution processes [3,5,18,21-25]. It is a two parameter distribution function which can be expressed by the following function:

$$
y=F(x)=\left(\frac{x}{k}\right)^{n}
$$

where:

$y=F(x)=$ cumulative undersize distribution function

$x=$ particle size

$k=$ the maximum size of particles which corresponding to $100 \%$

cumulative distribution undersize 
$n=$ a characteristic constant of the material under analysis and gives a measure of steepness of cumulative distribution curve

Equation (9) may be rewritten as follows:

$$
x=k y^{\frac{1}{n}}
$$

The frequency distribution function can be obtained by differentiation of equation (9) as follows:

$$
f(x)=\frac{d y}{d x}=\frac{d F(x)}{d x}=\frac{n}{k^{n}} x^{n-1}
$$

Equation (9) can be reduced to the following formula:

$$
\operatorname{Ln}(y)=n \operatorname{Ln}(x)-n \operatorname{Ln}(k)
$$

Equation (12) gives a straight line if $\operatorname{Ln}(y)$ is plotted against $\operatorname{Ln}(x)$ where $\mathrm{n}$ is the slope of the best fitting line of the data and - $n \operatorname{Ln}(k)$ is the intercept part of the $L n$ (y) axis. Both the constants $n$ and $k$ can be obtained easily using the least squares method through computer software.

The various mean sizes available in Table 1 may be easily determined from Gates-Gaudin-Schuhmann distribution function as explained below. For example, if it is required to obtain the arithmetic mean size, this may be evaluated by integration of equations (7) or (8) after replacing $m(x)$ by $x$. In this case, the equations may be rewritten as follows:

$$
m\left(\left(\begin{array}{l}
- \\
x
\end{array}\right)_{a}\right)=\int_{0}^{\infty} x f(x) d x
$$

or:

$$
m\left(\left(\begin{array}{l}
- \\
x
\end{array}\right)_{a}\right)=\int_{0}^{1.0} x d y
$$

From integration rules, it is better and easier to use equation (14). Replace the value of $x$ in equation (10) by $y$ and then substitute in equation (14), this change the latter one into the following form:

$$
m\left(\left(\begin{array}{l}
x \\
)_{a}
\end{array}\right)=k \int_{0}^{1.0} y^{\frac{1}{n}} d y\right.
$$

By integration of the previous equation and substitution the values of integration limits of y by $(0,1.0)$, the final expression of arithmetic mean may be determined as follows:

$$
(\bar{x})_{a}=m\left((\bar{x})_{a}\right)=\frac{n k}{n+1}
$$

To determine the values of other mean sizes, the value of $m(x)$ in equation (8) is substituted by $x^{2}$ (quadratic mean), $x^{3}$ (cubic mean), $\operatorname{Ln}(x)$ (geometric mean), and $1 / x$ (harmonic mean). Hence, by applying the same previous procedure, the final expressions of different mean sizes may be obtained as follows:

$$
(\bar{x})_{q}=\sqrt{m\left((\bar{x})_{q}\right)}=k \sqrt{\frac{n}{n+2}}
$$




$$
\begin{aligned}
& (\bar{x})_{c}=\sqrt[3]{m\left((\bar{x}){ }_{c}\right)}=k \sqrt[3]{\frac{n}{n+3}} \\
& \left.(x)_{g}=e^{m((x)}{ }^{m}\right)=e^{\frac{n \operatorname{Ln}(k)-1}{n}} \\
& (\bar{x})_{h}=\frac{1}{-}=\frac{(n-1) k}{n} \\
& m\left((x)_{h}\right)
\end{aligned}
$$

Although the mean particle size of the distribution (MPSD) is more convenient and valuable than the other measures, because it takes into consideration the complete distribution of the sizes and their corresponding percentages, this measure has some drawbacks with Gates-Gaudin-Schuhmann distribution model. Firstly, it is possible to obtain the same value of this measure with different distributions. This may be occurred if the distributions have corresponding values of the model constants, $n$ and $k$. Also, this measure may have a negative value of the harmonic mean if the value of the steepness of cumulative distribution curve of the data, $\mathrm{n}$ is lesser than the unity.

\section{Determination of the Mean of Particle Size Distribution (MPSD) Using Rosin-Rammler Distribution Model:}

The Rosin-Rammler distribution function is a commonly used model which is usually applied to evaluate the particle size distribution data. The Rosin-Rammler function is particularly suited for representing particles generated by grinding, milling and crushing operations. This model has long been used by many researchers $[2,3,5,22,26]$ to describe the particle size distribution of powders of various types and sizes. It is a two parameter distribution model and can be expressed by the following general equation:

$$
y=F(x)=1-\exp \left[-\left(\frac{x}{c}\right)^{m}\right]
$$

where:

$y=F(x)=$ cumulative undersize distribution function

$x \quad=$ particle size

$c \quad=\quad$ the particle size corresponding to $63.2 \%$ cumulative distribution undersize

$m=$ a characteristic constant of the material under analysis and gives a measure of steepness of cumulative curve

Equation (21) may be rewritten as follows:

$$
x=c[-\operatorname{Ln}(1-y)]^{(1 / m)}
$$

The frequency distribution function can be obtained by differentiation of equation (21) as follows: 


$$
f(x)=\frac{d y}{d x}=\frac{d F(x)}{d x}=\frac{m}{c^{m}}(x)^{m-1} \exp \left[-\left(\frac{x}{c}\right)^{m}\right]
$$

Equation (21) can be reduced to the following equation:

$$
\log \left[\operatorname{Ln}\left(\frac{1}{1-F(x)}\right)\right]=m \log (x)-m \log (c)
$$

Equation (24) gives a straight line if $\log [\operatorname{Ln}(1 /(1-F(x)]$ was plotted against $\log (\mathrm{x})$ where $\mathrm{m}$ is the slope of the best fitting line of the data and $-m \log (c)$ is the intercept part of the $\log [\operatorname{Ln}(1 /(1-F(x)]$ axis. Both the constants $m$ and c can be obtained easily using the least squares method through a computer program.

The various mean sizes available in Table 1 can be determined from RosinRammler equation as explained below. For example, if it is required to obtain the arithmetic mean particle size. This may be evaluated by integration of equations (13) or (14) after replacing of $m(x)$ by $x$. Then, substitution the value of $y$ by $x$ from equation (22) into equation (14). This will result the following form:

$$
m\left((x)_{a}\right)=c \int_{0}^{1.0}[-\operatorname{Ln}(1-y)]^{(1 / m)} d y
$$

It can be decided that it is so difficult to determine the value of above integration directly but it may be obtained indirectly with a mathematical procedure by aiding a computer program. After integration of the above equation and substitution the values of integration limits of $y$ by $(0,1.0)$, the final expression of arithmetic mean may be determined in a final expression as follows:

$$
\begin{aligned}
(x)_{a}=c \exp & {[0.0813298-(0.0607635 m)+(1.3431264 / \sqrt{m})} \\
& -(1.0604682 \operatorname{Ln}(m) / m)-(1.3636892 / m)]
\end{aligned}
$$

By executing the same previous procedure, the other mean particle sizes may be determined. This can be carried out by substituting $m(x)$ in equation (8) by $x^{2}$ (quadratic mean), $x^{3}$ (cubic mean), Ln $(x)$ (geometric mean), and $1 / x$ (harmonic mean). The final expressions of different mean sizes can be obtained by the following equations:

$$
\begin{aligned}
(\bar{x})_{q}= & c \sqrt{\exp [0.6337644-(0.0657717 \mathrm{~m})-(1.5545005 \operatorname{Ln}(\mathrm{m}) / \mathrm{m})} \\
(\bar{x})_{C}= & c \sqrt[3]{\begin{array}{l}
\exp [1.4692305+(0.0252045 \mathrm{~m})-(0.4964976 \operatorname{Ln}(\mathrm{m})) \\
-(2.9997296 \operatorname{Ln}(m) / m)+(0.2973719 / m)]
\end{array}} \\
(\bar{x})_{h}= & c /\left[\exp \left[\{-259.515-188.284 m)+\left(71.242 \mathrm{~m}^{2}\right)\right\} /\right. \\
& \left.\left.\left\{1+(104.378 * m)-\left(645.988 * m^{2}\right)\right\}\right]\right]
\end{aligned}
$$

Finally, the geometric mean can be expressed by the following equation:

$$
m\left((\bar{x})_{g}\right)=\int_{0}^{1.0} \operatorname{Ln}[c(-\operatorname{Ln}(1-y))]^{(1 / m)} d y
$$


It is found that it is not possible to solve this equation mathematically and hence, the value of above integration can not be determined. Hence, it can be decided that the geometric mean value of a particle size distribution using Rosin-Rammler model can not be derived mathematically.

\section{RESULTS AND DISCUSSION}

\section{Illustrated Example on the Estimation of MPSD from GGS and RR Models:}

Four data sets of different particle size distribution are available in the present study. The values of the weight percentages of different particle size fractions, together with the cumulative weight pass percentages are listed in Table 2. The cumulative weight pass percentages, i.e. cumulative undersize distribution function, $F(x)$ versus particle size, $x$ are shown also in Figure 2.

From Table 2 and Figure 2, it can be revealed that the different data sets have different distributions of particle sizes. Furthermore, it was found that the different data sets have the same values of median $\left(\mathrm{x}_{50}=305 \mu \mathrm{m}\right)$.

\section{The procedure of calculation of MPSD from GGS and RR models}

The procedure of calculation of different means of a particle size distribution from Gates-Gaudin-Schuhmann and Rosin-Rammler models can be summarized in the following simple steps:

1. Calculation of the cumulative distribution undersize of different particle sizes, $F(x)$ of the different data sets as shown in Table $\mathbf{2}$ and Figure 2.

2. For GGS model, $\operatorname{Ln}[F(x)]$ is plotted versus $\operatorname{Ln}(x)$ and the least squares regression analysis through computer software is used to fit the best straight line to the data points and hence, the values of GGS parameters $(n \& k)$ are estimated. The correlation coefficient may be used as the parameter for goodness of fit.

3. The values of these parameters are introduced into the formulas 16 through 20 to estimate the values of arithmetic, quadratic, cubic, geometric, and harmonic means of the different data sets.

4. In the case of RR model, $\log [\operatorname{Ln}[1 /(1-F(x))]]$ is plotted against $\log [x]$ and hence the model parameters $(m \& c)$ can be determined using the least squares regression method through a computer software.

5. The obtained values of RR parameters of the studied data sets are introduced into the expressions 26 through 29 to compute the values of arithmetic, quadratic, cubic, and harmonic means. 
Table 2: Particle size distributions of the different data sets

\begin{tabular}{|c|c|c|c|c|c|c|c|c|}
\hline \multirow{2}{*}{\begin{tabular}{|c|} 
size fraction, \\
$\mu \mathrm{m}$
\end{tabular}} & \multicolumn{2}{|c|}{ Data set 1} & \multicolumn{2}{|c|}{ Data set 2} & \multicolumn{2}{|c|}{ Data set 3} & \multicolumn{2}{|c|}{ Data set 4} \\
\hline & $w t ., \%$ & c.w.p.\% & $w t ., \%$ & c.w.p.\% & $w t ., \%$ & c.w.p.\% & $w t ., \%$ & c.w.p.\% \\
\hline$(+500)$ & 27.64 & 100 & 21.68 & 100 & 16.25 & 100 & 12.79 & 100 \\
\hline$(-500+400)$ & 10.16 & 72.36 & 12.63 & 78.32 & 14.60 & 83.75 & 15.61 & 87.21 \\
\hline$(-400+315)$ & 10.79 & 62.20 & 13.88 & 65.69 & 16.95 & 69.15 & 19.11 & 71.60 \\
\hline$(-315+250)$ & 9.65 & 51.41 & 12.20 & 51.80 & 14.68 & 52.20 & 16.41 & 52.49 \\
\hline$(-250+200)$ & 8.19 & 41.76 & 9.87 & 39.60 & 11.28 & 37.52 & 12.12 & 36.08 \\
\hline$(-200+160)$ & 6.95 & 33.57 & 7.85 & 29.73 & 8.36 & 26.24 & 8.53 & 23.96 \\
\hline$(-160+125)$ & 6.28 & 26.62 & 6.55 & 21.88 & 6.42 & 17.88 & 6.16 & 15.44 \\
\hline$(-125+100)$ & 4.53 & 20.33 & 4.34 & 15.32 & 3.89 & 11.46 & 3.49 & 9.28 \\
\hline$(-100+080)$ & 3.60 & 15.80 & 3.17 & 10.99 & 2.61 & 7.58 & 2.20 & 5.79 \\
\hline$(-080+063)$ & 3.00 & 12.20 & 2.42 & 7.82 & 1.82 & 4.97 & 1.45 & 3.58 \\
\hline$(-063)$ & 9.20 & 9.20 & 5.41 & 5.41 & 3.15 & 3.15 & 2.13 & 2.13 \\
\hline Sum & 100 & & 100 & & 100 & & 100 & \\
\hline
\end{tabular}

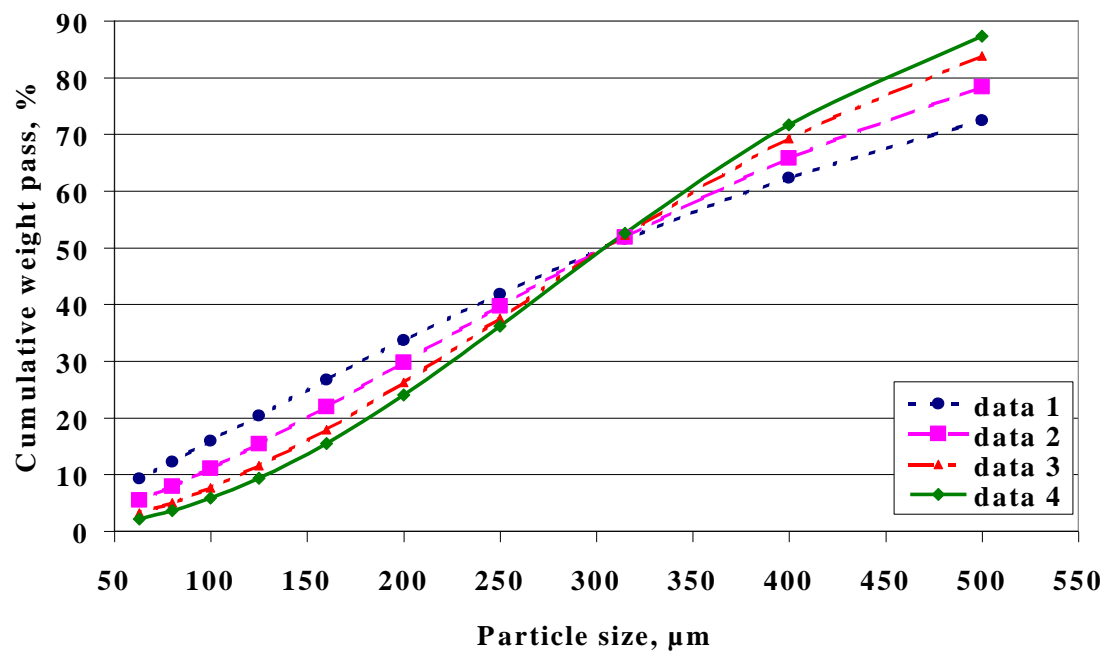

Fig. 2: Particle size distribution of the different data sets 


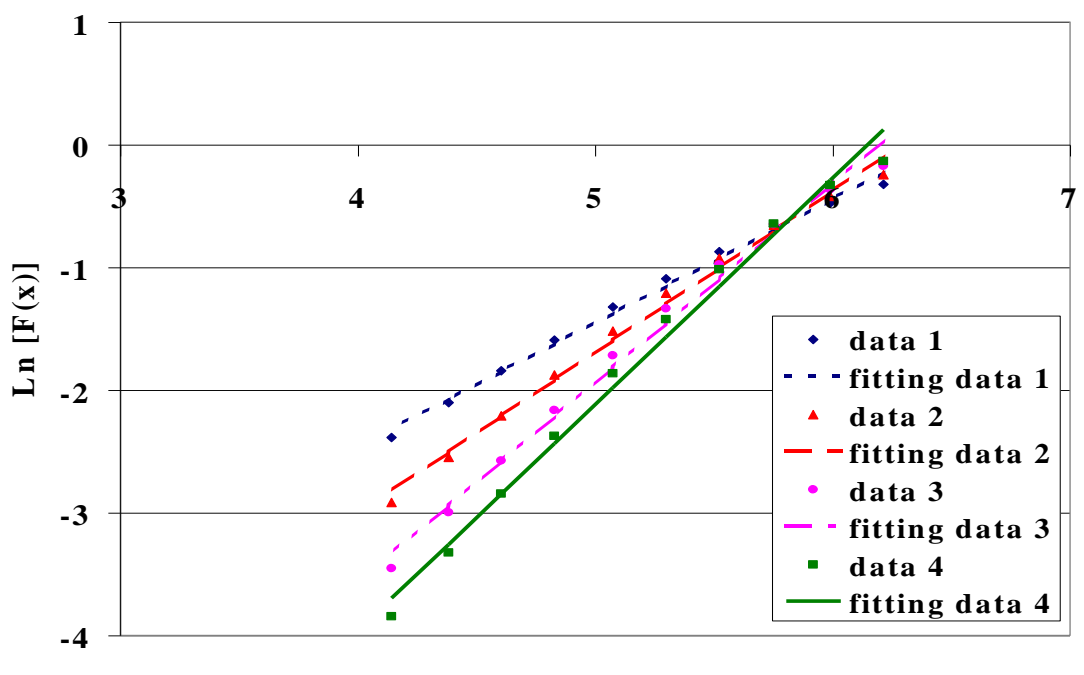

$\operatorname{Ln}(\mathbf{x})$

Fig. 3: Fitting of the studied data sets to Gates-Gaudin-Schuhmann model

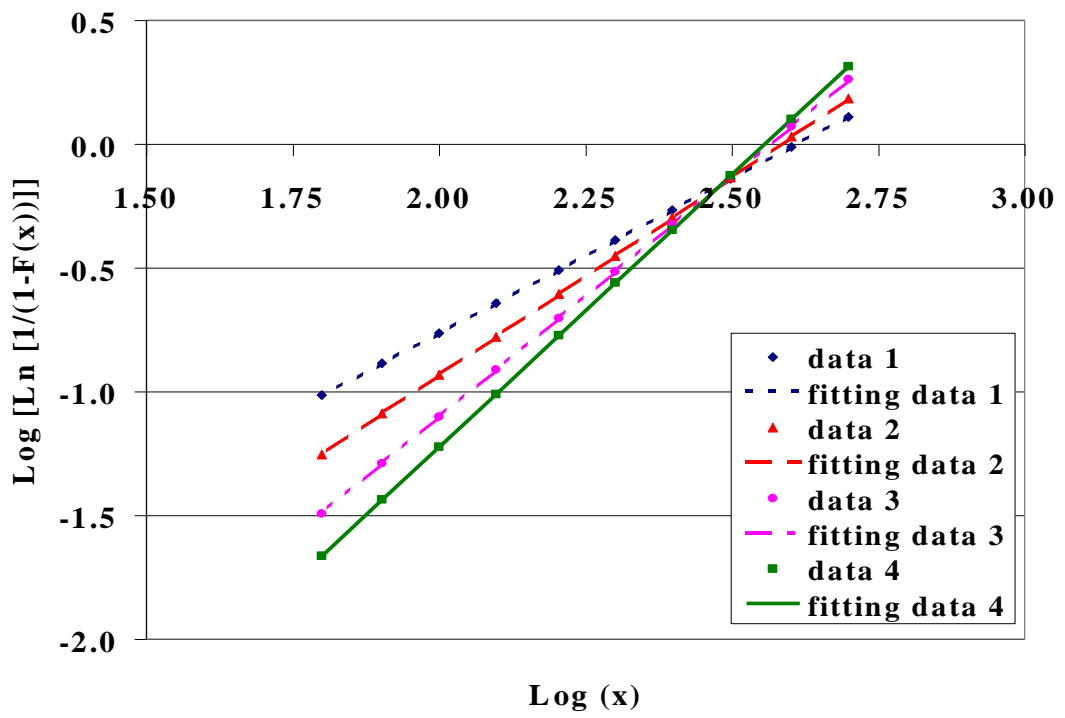

Fig. 4: Fitting of the studied data sets to Rosin-Rammler model

Figures 3 and 4 illustrate the fitting of the studied data sets to GGS and RR models, respectively. A Summary of the particle size distribution parameters obtained from GGS and RR models, as well as, the corresponding correlation coefficients of the best-fit straight lines of the studied data sets are tabulated in Table 3. From the observations in Figures 3 and $\mathbf{4}$ and the corresponding correlation coefficient, one can decide that the two models provides a good representation for all the available data sets although the RR model provides a better fit to the data than GGS does. 
Table 3: Summary of the particle size distribution parameters obtained from GatesGaudin-Schuhmann and Rosin-Rammler models, as well as, the corresponding correlation coefficients of the best-fit straight lines of the studied data sets

\begin{tabular}{|l|c|c|c|c|c|c|}
\cline { 2 - 7 } \multicolumn{1}{c|}{} & \multicolumn{2}{c|}{ Gates-Gaudin-Schuhmann model } & \multicolumn{3}{c|}{ Rosin-Rammler model } \\
\cline { 2 - 7 } \multicolumn{1}{c|}{} & $\boldsymbol{n}$ & $\boldsymbol{k}, \boldsymbol{\mu m}$ & $\boldsymbol{R}^{\mathbf{2}}$ & $\boldsymbol{m}$ & $\boldsymbol{c}, \boldsymbol{\mu m}$ & $\boldsymbol{R}^{\mathbf{2}}$ \\
\hline Data set 1 & 1.00981 & 624.34 & 0.99453 & 1.25212 & 408.31 & 0.99991 \\
Data set 2 & 1.31632 & 536.42 & 0.99283 & 1.59697 & 384.60 & 0.99988 \\
Data set 3 & 1.62478 & 489.27 & 0.99119 & 1.94242 & 368.65 & 0.99996 \\
Data set 4 & 1.84511 & 467.60 & 0.99004 & 2.19697 & 360.78 & 0.99994 \\
\hline
\end{tabular}

The median size $\left(\mathrm{x}_{50}\right)$ of the different particle size distribution data sets were determined from graphical representation of data, GGS, and RR models. The obtained results are listed in Table 4 and represented in Figure 5, where it can be revealed that the values of median size are nearly the same for the different studied data sets when these values are determined from graphical representation of data shown in Figure 2 and also from RR model. Furthermore, there is a clear difference between the values of this measure when they are determined from GGS model compared with RR model for the different data sets. This means that the RR model is more reliable to fit the available data sets than GGS model does.

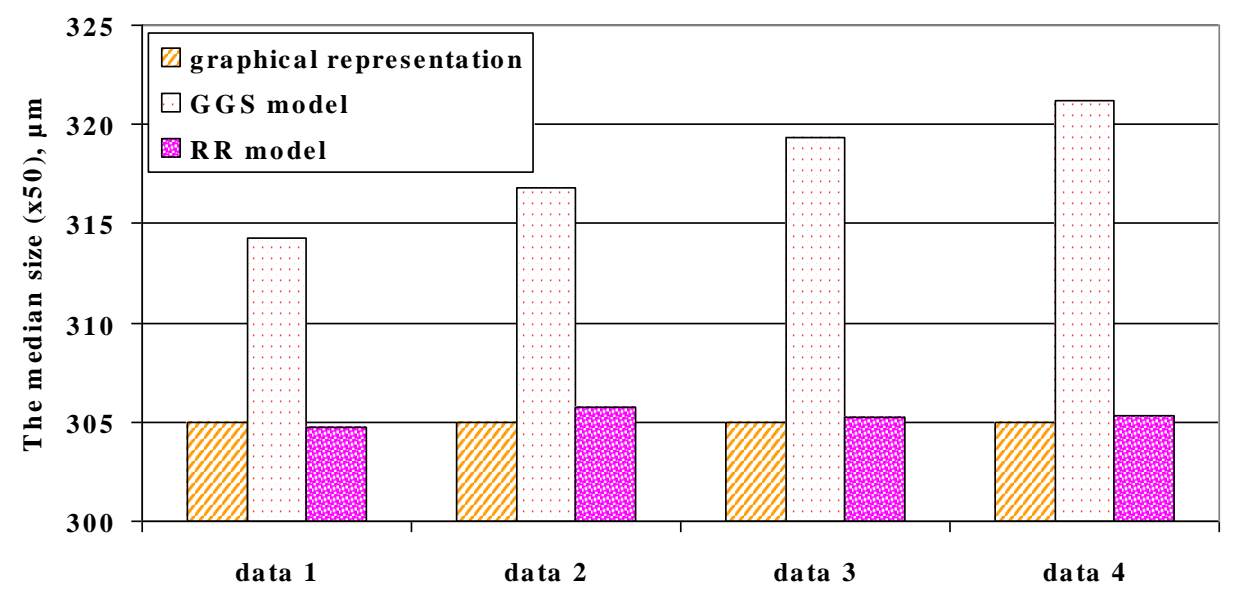

Fig. 5: Comparison of the values of median size (x50) obtained from graphical representation of data, Gates-Gaudin-Schuhmann, and Rosin-Rammler models 
Table 4: The median size $\left(\mathrm{x}_{50}\right)$ of the different particle size distributions data sets determined from graphical representation of data, Gates-Gaudin-Schuhmann, and Rosin-Rammler models

\begin{tabular}{|c|c|c|c|}
\cline { 2 - 4 } \multicolumn{1}{c|}{} & $\begin{array}{c}\text { Graphical representation } \\
\text { of data }\end{array}$ & $\begin{array}{c}\text { GGS } \\
\text { model }\end{array}$ & $\begin{array}{c}\text { RR } \\
\text { model }\end{array}$ \\
\cline { 2 - 4 } & $\boldsymbol{x}_{\mathbf{5 0}, \boldsymbol{\mu m}}$ & $\boldsymbol{x}_{\mathbf{5 0}, \boldsymbol{\mu m}}$ & $\boldsymbol{x}_{\mathbf{5 0}}, \boldsymbol{\mu m}$ \\
\hline Data set 1 & 305 & 314.28 & 304.69 \\
Data set 2 & 305 & 316.82 & 305.73 \\
Data set 3 & 305 & 319.36 & 305.26 \\
Data set 4 & 305 & 321.16 & 305.34 \\
\hline
\end{tabular}

\section{Comparison of different means estimated from GGS and RR models}

The values of arithmetic, quadratic, cubic, and harmonic mean sizes of the different particle size distribution data sets estimated from Gates-Gaudin-Schuhmann and Rosin-Rammler models are shown in Figures 6 through 9. These results are also presented in Table 5.

Comparison of the values of arithmetic, quadratic, and cubic mean sizes revealed that there are small differences between the lowest and highest values of these means for different data sets when they are evaluated from GGS model although there are clear differences in the behavior of the available data sets as shown in Figure $\mathbf{2}$ and then they should have different values of means. On the other hand, there are clear differences between the lowest and highest values of these measures if they are estimated from RR model. This difference may reach to $20 \%$ with arithematic mean size, $32 \%$ with quadratic mean size, and $42 \%$ with cubic mean size between different data sets. This means that RR model is more reliable to evaluate the means of a particle size distribution than GGS does.

Referring to Figure 9 which illustrates a comparison of the values of harmonic mean size estimated from the two models for the different data sets, it can be revealed that there are clear differences between the lowest and highest values of this measure for different data sets whichever they are computed from GGS or RR models. From Figure 9, it can be also shown that the two models give a reverse behavior of this measure with the different data sets. Moreover, RR model gives a logical behavior for the different data sets because the behavior of harmonic mean should be in a reverse of the behavior of arithmetic mean and this conclusion is in an agreement with the results obtained from RR model.

From the above discussions, it is recommended to select RR model to be applied in estimation of the different means of a particle size distribution because it fits the available data better than the GGS model, as well as, it determines the correct values and exerts the actual differences between the different means of different particle size distribution data sets. 


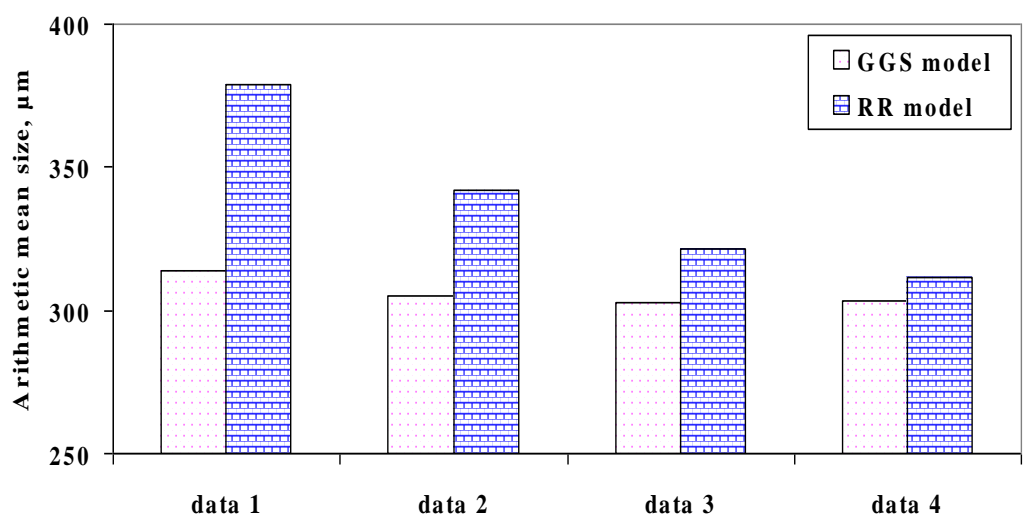

Fig. 6: Comparison of the values of arithmetic mean size estimated from GatesGaudin-Schuhmann and Rosin-Rammler models for the different data sets

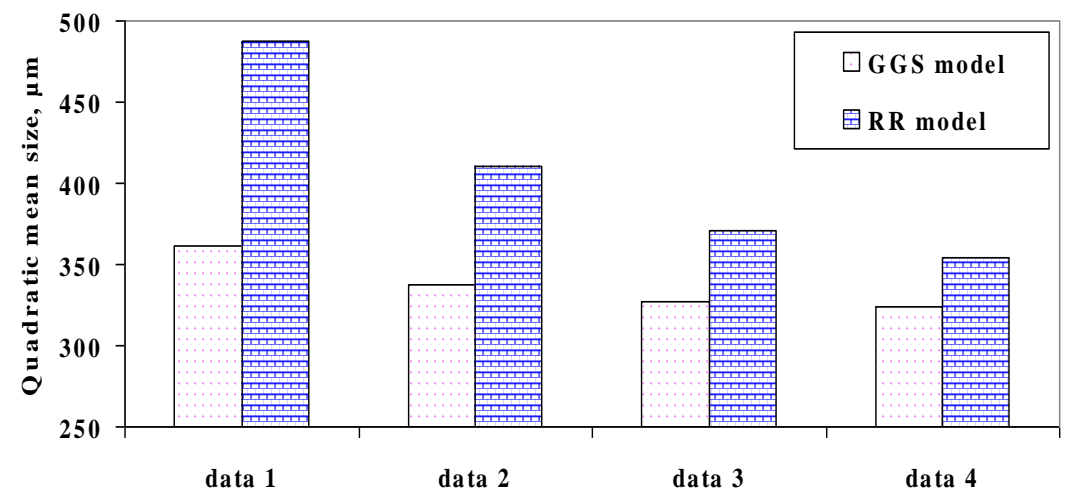

Fig. 7: Comparison of the values of quadratic mean size estimated from Gates-GaudinSchuhmann and Rosin-Rammler models for the different data sets

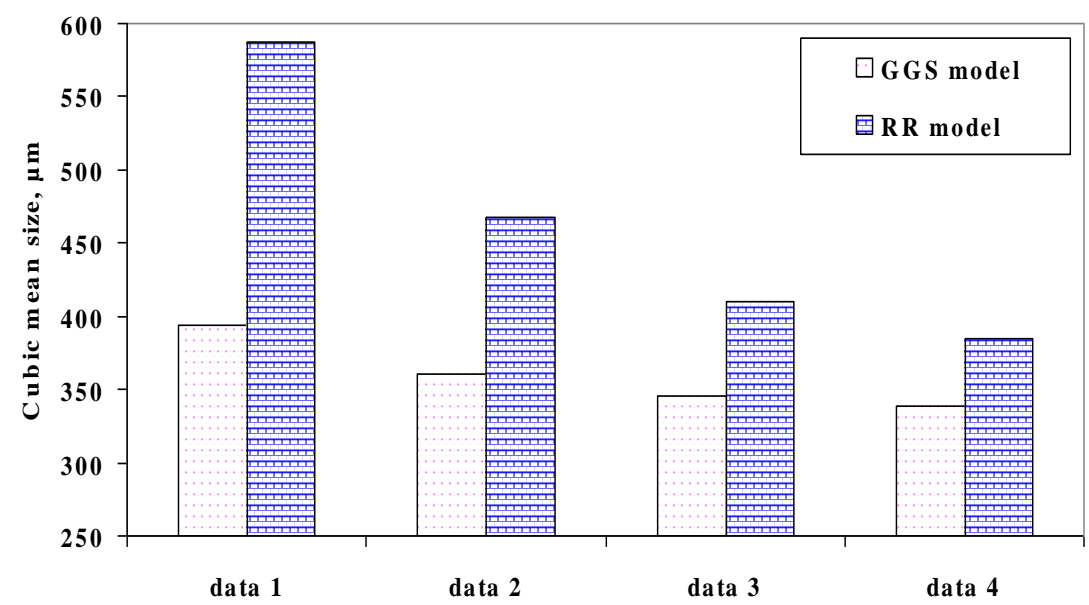

Fig. 8: Comparison of the values of cubic mean size estimated from Gates-GaudinSchuhmann and Rosin-Rammler models for the different data sets 


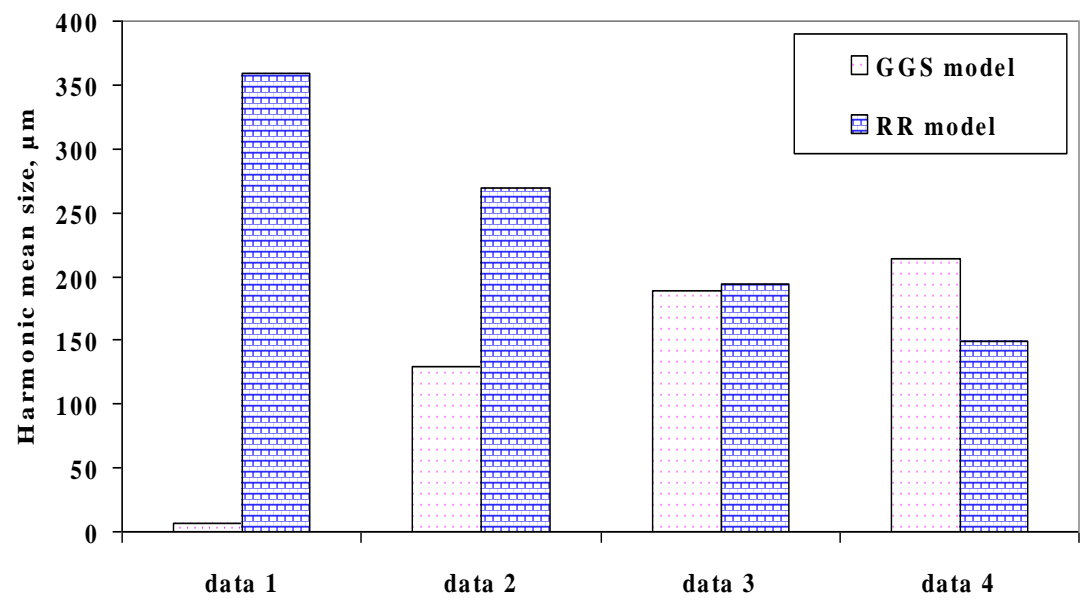

Fig. 9: Comparison of the values of harmonic mean size estimated from Gates-GaudinSchuhmann and Rosin-Rammler models for the different data sets

Table 5: The values of arithmetic, quadratic, cubic, and harmonic means of the different particle size distribution data sets estimated from Gates-Gaudin-Schuhmann and Rosin-Rammler models

\begin{tabular}{|c|c|c|c|c|c|c|c|c|}
\cline { 2 - 9 } \multicolumn{1}{c|}{} & \multicolumn{2}{c|}{$\begin{array}{c}\text { Arithmetic } \\
\text { mean } \\
\text { size, } \boldsymbol{\mu m}\end{array}$} & \multicolumn{2}{c|}{$\begin{array}{c}\text { Quadratic mean } \\
\text { size, } \boldsymbol{\mu m}\end{array}$} & \multicolumn{2}{c|}{$\begin{array}{c}\text { Cubic mean } \\
\text { size, } \boldsymbol{\mu m}\end{array}$} & \multicolumn{2}{c|}{$\begin{array}{c}\text { Harmonic } \\
\text { mean } \\
\text { size, } \boldsymbol{\mu m}\end{array}$} \\
\cline { 2 - 10 } & $\boldsymbol{G} \boldsymbol{S}$ & $\boldsymbol{R} \boldsymbol{G}$ & $\boldsymbol{G} \boldsymbol{S}$ & $\boldsymbol{R} \boldsymbol{R}$ & $\boldsymbol{G} \boldsymbol{G}$ & $\boldsymbol{R} \boldsymbol{R}$ & $\boldsymbol{G} \boldsymbol{S}$ & $\boldsymbol{R} \boldsymbol{R}$ \\
\hline Data set 1 & 313.69 & 379.19 & 361.63 & 487.99 & 394.27 & 586.80 & 6.06 & 358.95 \\
Data set 2 & 304.84 & 341.92 & 337.96 & 409.94 & 361.07 & 467.25 & 128.91 & 268.90 \\
Data set 3 & 302.87 & 321.28 & 327.57 & 371.06 & 345.24 & 409.64 & 188.14 & 194.06 \\
Data set 4 & 303.25 & 311.57 & 323.91 & 354.18 & 338.93 & 384.94 & 214.17 & 149.36 \\
\hline
\end{tabular}

\section{CONCLUSIONS}

The following conclusions may be drawn from this research:

1. The different means (arithmetic, quadratic, cubic, geometric, and harmonic) of a particle size distribution can be easily estimated using Gates-Gaudin-Schuhmann and Rosin-Rammler models.

2. The two models provide a very good representation for all the available data sets although the RR model provides a better fit to the data than GGS does.

3. There are small differences between the values of different means for different data sets when they are evaluated from GGS model.

4. There are clear differences between the lowest and highest values of arithmetic, quadratic, and cubic means of different data sets if they are estimated from RR model. This difference may reach to $20 \%$ with arithematic mean size, $32 \%$ with quadratic mean size, and $42 \%$ with cubic mean size. 
5. There are clear differences between the lowest and highest values of harmonic mean for different data sets whichever they are computed from GGS or RR models. The two models give a reverse behavior of this measure with the different data sets.

6. It is recommended to select RR model to be applied in estimation of the different means of a particle size distribution because it fits the available data better than the GGS model, as well as, it determines the correct values and exerts the actual differences between the different means of different particle size distribution data sets.

\section{REFERENCES}

1. Svarovsky, L., "Characterization of particles suspended in liquids", In: SolidLiquid Separation, Butterworth-Heinemann, Oxford, England, $4^{\text {th }}$ ed., Ch. 2, pp. 30-65, (2000).

2. Djamarani, K.M. and Clark, I.M., "Characterization of particle size based on fine and coarse fractions", Powder Technology, Vol. 93, pp. 101-108, (1997).

3. Garcia, A.M., Cuerda-Correa, E.M. and Diaz-Diez, M.A., "Application of the Rosin-Rammler and Gates-Gaudin-Schuhmann models to the particle size distribution analysis of agglomerated coke", Materials Characterization, Vol. 52, pp. 159-164, (2004).

4. Hsih, C.S., Wen, S.B. and Kuan, C.C., "An exposure model for valuable components in comminuted particles", Int. J. Mineral Process., Vol. 43, pp. 145165, (1995).

5. Wills, B.A., "Particle size analysis", In: Mineral Processing Technology, Pergamon Press, Oxford, England, 5th ed., Ch. 4, pp. 181-225, (1992).

6. Teipel, U., Leisinger, K. and Mikonsaari, I., "Comminution of crystalline material by ultrasonics", Int. J. Mineral Process., Vol. 74S, pp. S183-190, (2004).

7. Wen, S.B., Hsih, C.S. and Kuan, C.C., "The application of a mineral exposure model in a gold leaching operation", Int. J. Mineral Process., Vol. 46, pp. 215-230, (1996).

8. Fuerstenau, D.W., Kapur, P.C., Schoenert, K. and Marktscheffel, M., "Comparison of energy consumption in the breakage of single particles in a rigidly mounted roll mill with ball mill grinding", Int. J. Mineral Process., Vol. 28, pp. 109-125, (1990).

9. Kapur, P.C. and Fuerstenau, D.W., "Energy-size reduction laws revisited", Int. J. Mineral Process., Vol. 20, pp. 45-57, (1987).

10. Shook, C.A. and Roco, M.C., "Basic concepts for single-phase fluids and particles", In: Slurry Flow (Principles and Practice), Butterworth-Heinemann, Boston, U.S.A., Ch. 1, pp. 1-25, (1991).

11. Fang, Z., Patterson, B.R. and Turner, M.E., "Modeling particle size distribution by the Weibull distribution function", Materials Characterization, Vol. 31, pp. 177182, (1993).

12. Xiang, Y. Zhang, J. and Liu, C., "Verification for particle size distribution of ultrafine powders by the SAXS method", Materials Characterization, Vol. 44, pp. 435-439, (2000). 
13. Dierickx, D., Basu, B., Vleugels, J. and Van der Biest, O., "Statistical extreme value modeling of particle size distributions: experimental grain size distribution type estimation and parameterization of sintered zirconia", Materials Characterization, Vol. 45, pp. 61-70, (2000).

14. Ramakrishnan, K.N., "Investigation of the effect of powder particle size distribution on the powder microstructure and mechanical properties of consolidated material made from a rapidly solidified $\mathrm{Al}, \mathrm{Fe}, \mathrm{Ce}$ alloy powder: part I. Powder microstructure", Materials Characterization, Vol. 33, pp. 119-128, (1994).

15. Ramakrishnan, K.N., "Investigation of the effect of powder particle size distribution on the powder microstructure and mechanical properties of consolidated material made from a rapidly solidified Al, Fe, Ce alloy powder: part II. Mechanical properties", Materials Characterization, Vol. 33, pp. 129-134, (1994).

16. Rao, S.S., "Stochastic programming", In: Engineering Optimization (Theory and Practice), New Age International (P) Limited, New Delhi, India, 3rd ed., Ch. 11, pp. 715-767, (2004).

17. Kheifets, A.S. and Lin, I.J., "Energetic approach to kinetics of batch ball milling", Int. J. Mineral Process., Vol. 54, pp. 81-97, (1998).

18. Wu, S.Z., Chau, K.T. and Yu, T.X., "Crushing and fragmentation of brittle spheres under double impact test", Powder Technology, Vol. 143-144, pp. 41-55, (2004).

19. $\mathrm{Mu}$, Y., Lyddiatt, A. and Pacek, A.W., "Manufacture by water/oil emulsification of porous agarose beads: effect of processing conditions on mean particle size, size distribution and mechanical properties", Chemical Eng. and Process, Vol. 44, pp. 1157-1166, (2005).

20. Lech, M., Polednia, E. and Werszler, A., "Measurement of solid mean particle size using tomography", Powder Technology, Vol. 111, pp. 186-191, (2000).

21. Ouchiyama, N., Rough, S.L. and Bridgwater, J., "A population balance approach to describing bulk attrition", Chemical Eng. Science, Vol. 60, pp. 1429-1440, (2005).

22. Gbor, P.K. and Jia, C.Q., "Critical evaluation of coupling particle size distribution with the shrinking core model", Chemical Eng. Science, Vol. 59, pp. 1979-1987, (2004).

23. Choi, W.S., Chung, H.Y., Yoon, B.R. and Kim, S.S., "Applications of grinding kinetics analysis to fine grinding characteristics of some inorganic materials using composite grinding media by planetary ball mill", Powder Technology, Vol. 115, pp. 209-214, (2001).

24. Hosten, C. and San, O., "Reassessment of correlations for the dewatering characteristics of filter cakes", Minerals Engineering, Vol. 15, pp. 347-353, (2002).

25. Stamboliadis, E.Th., "A contribution to the relationship of energy and particle size in the comminution of brittle particulate materials", Minerals Engineering, Vol. 15, pp. 707-713, (2002).

26. Cheong, Y.S., Reynolds, G.K., Salman, A.D. and Hounslow, M.J., "Modeling fragment size distribution using two-parameter Weibull equation", Int. J. Mineral Process., Vol. 74S, pp. S227-S237, (2004). 
دراسة مقارنة لتحديد متوسط حجم الحبيبات بغرض عمل توصيف حقيقي للبيانات

\section{المتعلقة بالبيئة}

أحد أهم المراحل في الدراسات البيئية هي الحصول على توزيع كمي ونوعي دقيق للملوثات حيث أن هذه الدراسات تتطلب حساب حجم الحبييات بدقة عالية.

هناك الكثير من الباحثين يستخدمون الوسيط (x50) وهو حجم المنخل المناظر لنسبة مرور تراكمية

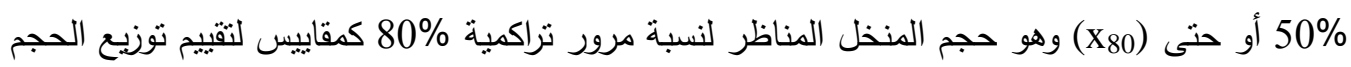

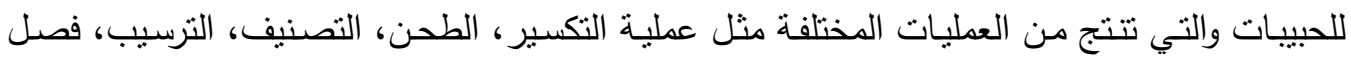
المواد الصلبة عن السائلة، أو حتى العطليات الناتجة عن تقييم أو دراسة شكل وتوزيع الملوث.

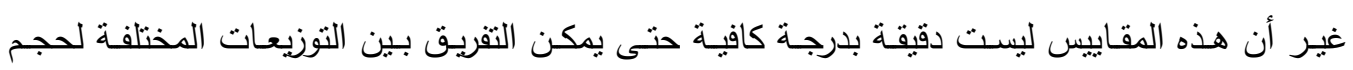

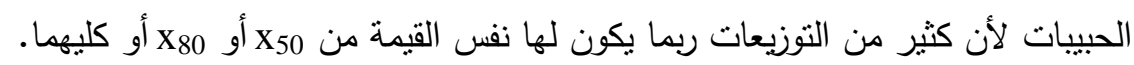

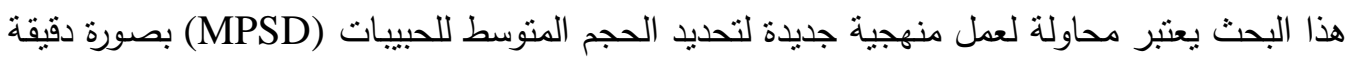

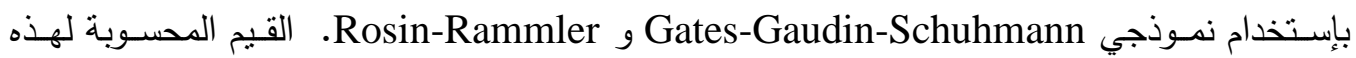
المقاييس نأخذ في الإعتبار ليس فقط الأحجام الفردية للحبيبات ولكن أيضا النسب الوزنية المناظرة لهم.

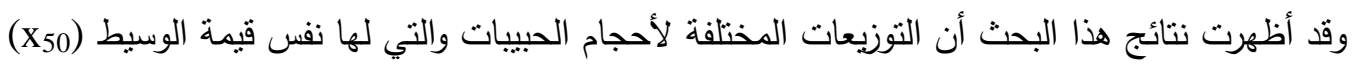
تعطى قيم مختلفة للمقياس المستخدم في هذا البحت (MPSD) وخصوصـا عند إستخدام معادلـة

.Rosin-Rammler

في هذا البحث تم أيضا الحصول على تعبيرات رياضية بسيطة والتي من خلالها أمكن حساب الحجم

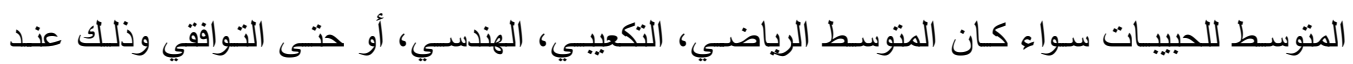
إستخدام أب من النموذجين المشار إليهم سابقا.

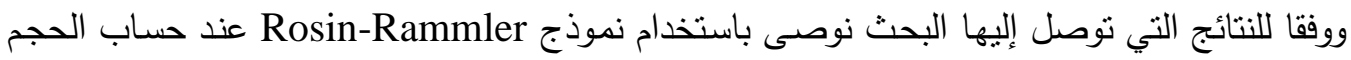
المنوسط للحبيبات حيث أن هذا النموذج يوفق البيانات بصورة أفضل من نموذج - Gates-Gaudin Schuhmann وفي نفس الوقت يمكن من خلاله حساب القيم الصحيحة وتعيين الفروقات الفعلية بين المتوسطات المختلفة للبيانات.

ويعد هذا البحث الجزء الأول من دراسـة سوف تتبع بعمل دراسـة حالة حقيقية لبيانات فعلية مرتبطـة 